RESEÑ A

\title{
La pregunta por el régimen político. Conversaciones chilenas. Arturo Fontaine, Fondo de Cultura Económica, 2021. 243 pp.
}

\author{
RESEÑADO POR \\ Christopher A. MArtínez ${ }^{1}$ \\ Universidad Católica de Temuco, Chile
}

El proceso de cambio constitucional que vive Chile ha despertado nuevamente la discusión sobre qué forma de gobierno debiera adoptar el país: presidencialismo, semipresidencialismo o parlamentarismo. La pregunta por el régimen político invita a los lectores a revisar y cuestionar sus posiciones al respecto. Escrito de manera inteligente y ágil, en un estilo accesible tanto para el público interesado en política como para una audiencia más académica, el libro provee información y reflexiones esenciales sobre cada forma de gobierno, sus ventajas y problemas asociados. Fontaine hace un análisis a la luz de la literatura comparada sobre regímenes políticos, lo cual complementa con experiencias de otros países y ejemplos concretos, manteniendo siempre su atención en Chile.

El libro se divide en tres partes. En la primera (capítulos I-IV), el autor centra su atención en las características, fortalezas y debilidades del presidencialismo, parlamentarismo y semipresidencialismo. Su principal énfasis estriba en desmentir algunos mitos y creencias incorrectas, tales como el hiperpresidencialismo chileno, la inherente inestabilidad política del presidencialismo, el mayor poder que tendría el parlamento en un sistema semipresidencial, entre otras. Asimismo, discute los potenciales efectos y problemas de la implementación del parlamentarismo y semipresidencialismo en Chile.

1. PhD en Ciencia Política por Loyola University Chicago (Estados Unidos). Actualmente, se desempeña como Profesor Asociado del Depto. de Sociología, Ciencia Política y Administración Pública de la U. Católica de Temuco, Chile. Email: christopher.martinez@uct.cl. 
La segunda parte (capítulos V-XI) profundiza en las raíces histórica y teóricas del presidencialismo en Estados Unidos. Se centra, por ejemplo, en el rol de los "padres fundadores" y sus creencias en el debate llevado a cabo en la Convención de Filadelfia, así como en los aspectos concretos del presidencialismo que comenzaba a cobrar vida en aquellos años. Esta sección será de gran interés a los estudiosos del presidencialismo en general, algo que el público más académico seguramente agradecerá.

La tercera parte y final (capítulos XII-XIV) se centra en aspectos específicos del presidencialismo en el contexto actual, en el que la democracia ha ido retrocediendo en el mundo. El análisis del gobierno parlamentario en la Hungría de Viktor Orbán ilustra los principales problemas y desafíos que representa la ola autocrática, más allá del tipo de régimen político existente. El capítulo XIV sobre recomendaciones y sugerencias para Chile es el más ambicioso de la tercera parte. Fontaine discute algunas modificaciones que debieran ser introducidas para fortalecer el funcionamiento del sistema político. Estas se relacionan con la modificación del calendario electoral -i.e., celebrar elecciones parlamentarias durante la segunda vuelta presidencial- y fortalecer a los partidos y sistema de partidos. El autor sugiere que estos son elementos clave para la gobernabilidad en Chile, incluso si se opta por reemplazar el sistema presidencial actual.

A pesar de que los capítulos de la primera parte harán dudar a quienes postulan un sistema parlamentario o semipresidencial para Chile, el argumento más convincente Fontaine lo detalla al final. Tal como reconoce el autor, el libro no busca determinar cuál es la mejor forma de gobierno, sino cuál de ellas es la más apta para la realidad e historia de Chile. Sobre esto, Fontaine apunta a la resistencia que podría causar en la ciudadanía el hecho de que se les arrebate el derecho a elegir al o la gobernante. Pues bajo un sistema parlamentario son las dirigencias partidarias las que asumen el rol de formar el gobierno, mientras que en el semipresidencialismo esto también podría ocurrir en caso de que el legislativo liderado por la oposición esté en desacuerdo con el presidente sobre el primer ministro y su gabinete.

El autor hace un comprehensivo análisis de datos, posturas e investigaciones científicas sobre los diferentes regímenes políticos alrededor del mundo, así como su potencial implementación en Chile. El libro es exhaustivo en su análisis al punto que logra incorporar en la discusión tanto la crisis que comenzó a vivir Chile en octubre de 2019, como el impacto del COVID-19 en la realidad nacional. Con todo, el libro no aborda la influencia de la "piñerización" en la discusión sobre el presidencialismo y sus propuestas de cambio.

Lo anterior ha dado fuerza a las posiciones que buscan flexibilizar el presidencialismo, o que incluso proponen su reemplazo, dado que no ha facilitado la salida anticipada del Presidente Sebastián Piñera. Incluso entre aquellos que apoyan el presidencialismo ha surgido, al menos, la duda sobre qué hacer con un presidente que 
no está a la altura de las circunstancias o que se transforma en un obstáculo para salir de una crisis política. En 22 ocasiones en las últimas cuatro décadas presidentes latinoamericanos han sido obligados a dejar el poder prematuramente. Esto es lo que la literatura en ciencia política denomina "presidentes fallidos", i.e., aquellos que son obligados a dejar el cargo, pero sin producir un quiebre democrático ${ }^{2}$. La discusión sobre acortar el mandato del Presidente Piñera ha tensionado incluso a la oposición. Mientras unos sugerían adelantar elecciones o derechamente la destitución del Presidente Piñera, otros mantenían la convicción de que el presidente de la república siempre debe cumplir su periodo principal, mientras algunos más indecisos dudaban qué hacer ante la ausencia de un liderazgo alternativo -tanto en el oficialismo como en la oposición- que pudiera tomar las riendas del país en caso de que el presidente fuera destituido.

Una respuesta parcial a la pregunta sobre el régimen político que plantea Fontaine, y sobre qué hacer con el presidente en casos de crisis como la actual, podría ser la adopción de la figura del vicepresidente dentro del presidencialismo, cuyo nombre se incluya en la papeleta al lado del o la candidata a la presidencia ${ }^{3}$. En casos de crisis política severa, en la cual la salida prematura del presidente se considere seriamente como una opción, la figura del vicepresidente daría continuidad al gobierno elegido popularmente, al menos hasta las próximas elecciones. Asimismo, solucionaría el dilema colectivo sobre quién asumiría en caso de vacancia, pues es más fácil estar de acuerdo sobre la remoción del presidente que sobre quién le sucederá. Finalmente, la figura del vicepresidente entregaría un mínimo de legitimidad a la nueva primera autoridad del país pues su nombre habrá sido votado popularmente.

Más allá de lo anterior, el libro de Arturo Fontaine es una notable sistematización de investigaciones clásicas y recientes sobre régimen político, lo cual hace de este una fuente esencial en cualquier programa académico sobre sistemas políticos comparados. Su principal efecto a corto plazo será el de influir en la discusión nacional y la nueva constitución. Sobre el debate actual en torno al régimen político, el autor agudamente observa que "El presidencialismo se vive en Chile, como es natural, con conciencia de sus imperfecciones y deficiencias, sintiendo el desgaste de lo próximo y acostumbrado. En cambio, ese nuevo régimen parlamentarista o semipresidencialista solo se imagina a la distancia" (pp. 22-23). Es decir, mientras existe relativa claridad de los problemas de nuestro presidencialismo, incluso exageradamente, se tienden a subestimar o invisibilizar las debilidades de los regímenes parlamentarios y semipresidenciales. El libro es exitoso al cuestionar inteligentemente estas creencias y supuestos. La pregunta sobre el régimen político, sin dudas, se convertirá en lectura obligada tanto para precursores y detractores del presidencialismo chileno.

2. MARTÍNEZ (2017).

3. Ver OLIVARES et al. (2020). 


\section{Referencias bibliográficas}

MARTÍNEZ, Christopher A. (2017): "Presidential Survival in Latin America: Rethinking the Role of Democracy". International Political Science Review No $38, \mathrm{pp} .40-$ 55 .

OLIVARES L., Alejandro, GONZÁLEZ-BUSTAMANTE, Bastián, TORO MAUREIRA, Sergio, ARELLANO, Juan Carlos, YANES-ROJAS, Anabel, ZURITA-TAPIA, José, LOPES, Amanda Vitoria, ROBELO GUZMÁN, Claudio, \& CANAVESI SOSA, Juan Bautista (2020): "Nuevos desafíos, enfoques y perspectivas para estudiar élites políticas”. Iberoamericana. № 20, pp. 229-259. 